\title{
Anterior interosseous nerve palsy: spontaneous recovery in two patients
}

\author{
CHRISTOPHER GARDNER-THORPE ${ }^{1}$
}

From the Regional Neurological Centre, Newcastle General Hospital, Newcastle upon Tyne

SYNOPSIS The case histories of two patients who developed an anterior interosseous nerve palsy apparently as a result of an external pressure injury are reported. Both patients recovered fully without surgical exploration, one 19 months and the other nine months after the onset. It is stressed that complete recovery may occur spontaneously.

Palsy due to lesions of the anterior interosseous nerve is rare. Most of the literature on the subject stems from orthopaedic sources: in particular, the work of Spinner (1972) is noteworthy. However, anterior interosseous nerve palsy may present to the neurologist as well as to the orthopaedic surgeon. The purpose of this paper is to report the case histories of two patients who developed it probably as a result of external pressure and to draw attention to the spontaneous recovery which may occur and which renders surgical exploration unnecessary.

USUAL ANATOMICAL FINDINGS (Davies and Coupland, 1967) The anterior interosseous nerve arises from the median nerve where the latter passes between the two heads of the pronator teres just below the elbow. The anterior interosseous nerve passes down the forearm and supplies three muscles-flexor pollicis longus, flexor digitorum profundus to the index and middle fingers, and pronator quadratus. Sensory fibres in the nerve arise from end-organs in the distal radio-ulnar joint and the wrist joint. The anterior interosseous nerve does not convey sensory fibres from end-organs in the skin and it may be regarded as a pure motor nerve for practical clinical purposes.

Palsy of the anterior interosseous nerve is characterized by weakness of flexion of the interphalangeal joint of the thumb and terminal interphalangeal joints of the index and middle

1 Present address: Department of Neurology, Royal Devon and Exeter Hospital (Wonford), Barrack Road, Exeter EX2 5DW. fingers, together with weakness of pronation when the elbow is flexed (in order to minimize pronation due to the action of pronator teres which is not weak). Sensory testing is normal as is power in the other muscles supplied by the median nerve-for example, abductor polliciso brevis. The characteristic clinical picture, there fore, is weakness of pinch together with inability actively to flex the interphalangeal joint of the thumb and the terminal interse phalangeal joint of the index finger. These joints become hyperextended and the proximal interphalangeal joints flexed. The index finger contacts the pulp of the thumb at a point situated more proximally than is normal. In some patients, pain and tenderness may be found in the proximal part of the forearm.

Anatomical anomalies Anomalies in the distribution of the anterior interosseous nerve are not uncommon (Wilson, 1954). The MartinGruber anastomosis (Martin, 1763; Gruber, 1870 ) is a communication between the motor fibres of the median nerve or its branches and the ulnar nerve in the forearm which occurs in $15 \%$ of limbs (Thompson, 1893). Approximately one Martin-Gruber anastomosis in two arises from the anterior interosseous nerve and therefore a lesion of that nerve can sometimes cause weakness of the ulnar-innervated small muscles of the hand (Mannerfelt, 1966). The part of the flexor digitorum profundus muscle which controls the index finger is usually supplied by the anterior interosseous nerve (Sunderland, 1945) but the 
part which controls the middle finger may be supplied by the median nerve, the ulnar nerve, or both. Flexor pollicis longus may also receive a branch directly from the median nerve but it seems that pronator quadratus is always supplied by the anterior interosseous nerve (Sunderland, 1968).

CAUSES OF PALSY OF ANTERIOR INTEROSSEOUS NERVE These may be summarized as follows:

1. Injury

a. Penetrating injuries Knife wounds, bullet wounds, and forearm venous injections. In one case, the palsy appeared 10 years after a stab wound (Spinner, 1972).

b. Supracondylar fracture of humerus in children Probably due to traction on the anterior interosseous nerve (Spinner and Schreiber, 1969) rather than to pressure on the posterior fibres of the median nerve (Lipscomb and Burleson, 1955).

c. Midshaft fracture of radius (Spinner, 1972).

d. Operative procedure for the relief of flexion contracture in the forearm (Page, 1923).

2. Muscle abnormality

a. Tendinous origin of the deep head of pronator teres, flexor digitorum profundus or palmaris longus (Spinner, 1972).

b. Accessory head of flexor pollicis longusGantzer's (1813) muscle-or accessory muscle and tendon between flexor digitorum superficialis and flexor pollicis longus.

\section{Vascular abnormality}

a. Scarring and swelling of muscle in Volkmann's ischaemia (Lipscomb and Burleson, 1955).

b. Aberrant radial artery.

c. Thrombosis of ulnar collateral vessels.

\section{Neuralgic amyotrophy}

Usually with evidence of involvement of other roots or nerves (Parsonage and Turner, 1948).

\section{Enlarged bicipital bursa}

DIFFERENTIAL DIAGNOSIS Other conditions may mimic anterior interosseous palsy. The more important of these include congenital absence of the deep flexor muscles (Spinner, 1972), rupture of the flexor tendons in rheumatoid disease and Kienbock's disease (James, 1949), and lesions of the medial root of the median nerve. The pronator syndrome (Seyffarth, 1951) may easily be distinguished, since the main trunk of the median nerve is compromised. O'Brien and Upton (1972) were the first to describe the detailed clinical neurophysiological investigation of a patient with anterior interosseous nerve palsy.

\section{Prognosis and treatment Many of the patients} discussed in the early case reports did not receive any specific treatment. Recovery was slow and the pathology not always known. Of the 36 patients with neuralgic amyotrophy discussed by Parsonage and Turner (1948) six had isolated weakness of flexor pollicis longus and flexor digitorum profundus: one patient recovered in a few months but the prognosis in the other five is not known. Partial recovery occurred after 12 and 23 months in the two patients reported by Kiloh and Nevin (1952) and the two patients described by Thomas (1962) recovered almost completely. Return of function started four to six weeks after a closed fracture of the forearm in the two patients described by Warren (1963) and power was normal after five and seven months. Partial recovery occurred after six and 18 months in the patients reported by Farber and Bryan (1968): one patient had worn a plaster cast for recurrent dislocation of the humerus before the anterior interosseous palsy developed.

The first description of an operation for this palsy has been attributed to Fearn and Goodfellow (1965) who divided a fibrous band and showed complete recovery after three months. However, Lipscomb and Burleson (1955) described the operations performed in four patients with a supracondylar fracture of the humerus primarily to relieve brachial artery compression but the outcome, so far as the anterior interosseous nerve was concerned, was the samecomplete recovery of function. Fibrous bands have been divided by other workers (Stern et al., 1967; Sharrard, 1968, Mills et al., 1969; Schmidt and Eiken, 1971) and recovery has followed after periods ranging from 10 days to four months.

Spinner $(1970,1972)$ and Spinner and Schreiber (1969) advocated exploration immediately after penetrating wounds and after an interval of six to eight weeks in other cases when there had not been any clinical or electromyo- 
graphic evidence of recovery. Spinner also pointed out that nerve and tendon transplant operations may help to normalize the function of the limb.

\section{CASE 1}

M.B. (N46796), a 35 year old housewife, first noticed pain in the left cubital fossa in February 1972. At about that time she had frequently been lifting her baby's carrycot into and out of the car, through the driver's door (right hand drive) and on to the back seat, but she does not recall whether she held the carrycot straps over her forearm. A few days after the appearance of the pain, which was accentuated by extension of the elbow, she noticed difficulty in moving the distal joints of the thumb and index finger although sensation in the hand and digits was quite normal. Typewriting, sewing, knitting, filing the nails, turning a key, lifting coins from a purse, and fastening buttons were particularly difficult manoeuvres. The pain in the cubital fossa persisted for approximately four weeks and the pain on extension of the elbow for six weeks. She was seen in August 1972 when weakness of the left flexor pollicis longus, flexor digitorum profundus to the index finger and pronator quadratus was found. Function had returned nearly to normal in March 1973. In September 1973 the patient was free of symptoms and clinical examination was entirely normal.

\section{CASE 2}

A.T. (N44651), a 40 year old fireman, underwent a craniotomy for the clipping of an anterior communicating artery aneurysm in January 1973. Soon after he had recovered from the operation-the exact time is not clear-he found that he could not flex the interphalangeal joint of the right thumb, particularly when he tried to flick the thumbpiece of his cigarette lighter.

Neurological examination failed to reveal any other abnormalities apart from the craniotomy scar. He had regained normal power in October 1973 without treatment.

\section{CLINICAL NEUROPHYSIOLOGICAL STUDIES}

A DISA 14A30 3-channel electromyograph was used for the clinical neurophysiological studies. The examinations were performed in a warm $\left(65-70^{\circ} \mathrm{C}\right)$ room and forearm skin temperatures were in the range $32-35^{\circ} \mathrm{C}$.

CONCENTRIC NEEDLE ELECTROMYOGRAPHY A concentric needle electrode was used to explore various muscles in the affected limb.
Case 1 Positive sharp wave potentials were recorded from pronator quadratus where motor unit potentials were of reduced amplitude in contrast to the normal potentials recorded from abductor pollicis brevis and flexor pollicis longus. The interference pattern on maximum voluntary activity was reduced both in density and amplitude in pronator quadratus and flexor pollicis longus: it was normal in abductor pollicis brevis.

Case 2 Fibrillation potentials were recorded from pronator quadratus. The interference pattern was reduced in flexor digitorum profundus and pronator quadratus but the remainder of the examination, including the abductor pollicis brevis, was normal.

MOTOR NERVE CONDUCTION Motor nerves were stimulated with saline-soaked pads placed on the skin overlying the nerves. The responses were recorded from concentric needle electrodes placed in the appropriate muscles. In both cases, the velocity in the fastest conducting fibres of the segments of nerves between elbow and wrist was normal (case $1:$ median $67 \mathrm{~m} / \mathrm{s}$, ulnar $66 \mathrm{~m} / \mathrm{s}$; case 2 : median $68 \mathrm{~m} / \mathrm{s}$ ).

In case 1 , the $M$ responses in the abductor pollicis brevis and abductor digiti minimi muscles were normal, whereas the response in flexor polliciso longus was unduly dispersed.

The latency to pronator quadratus was measured in both cases when the median nerve was stimulated at the elbow but the latencies did not differ significantly from those measured in two other patients without evidence of disorder of either median or anterior interosseous nerve.

NERVE ACTION POTENTIALS (case 1) The fingers were stimulated with ring electrodes. Nerve action potentials were recorded from saline-soaked pads placed on the skin overlying the appropriate nerve. Conduction in the median (index finger to wrist) and ulnar (little finger to wrist) nerves was normal as judged by the latency, amplitude and shape of the responses.

\section{DISCUSSION}

There seems to be little doubt, both on clinical grounds and as judged by the results of the clinical neurophysiological investigations, that these two patients had an anterior interosseous nerve lesion. It is not clear why the second patient had signs only in the thumb: damage had not occurred selectively to the fibres passing to the flexor pollicis longus since electromyographic abnormalities were found in other 
muscles usually supplied by the anterior interosseous nerve.

The palsy in both cases appeared to result from external pressure injury. The first patient probably carried the carrycot with the straps across her forearm. The second patient probably had some pressure lesion during the craniotomy although the evidence for this is only circumstantial.

Recovery occurred in both cases without treatment. The duration of recovery was longer (19 months) in the more severely affected patient (case 1) than in the other patient (nine months). Nevertheless, it must be emphasized that recovery was symptomatically complete in both. Surgical exploration was withheld, since the early reports of anterior interosseous nerve palsy indicate that spontaneous recovery does occur. There is a tendency nowadays to explore all entrapment neuropathies but it can be argued, in the case of the anterior interosseous nerve at least, that a period of several months should be allowed to elapse in order to see whether spontaneous recovery is going to occur. The case of penetrating injuries, of course, is different and in the acute stages these do not fall within the category of entrapment neuropathies.

Since exploration was not performed in the patients reported here, it is not known whether anatomical abnormalities in the area of origin of the anterior interosseous nerves were present. It seems unlikely that the patients were unusually susceptible to pressure palsies (Earl et al., 1964) since a family history of pressure palsies was not obtained and the electrophysiological studies in other nerves were normal. Furthermore, in none of the patients reported by Earl et al. (1964) did the anterior interosseous nerve appear to have been involved, perhaps because it is deeply situated and well-protected by the muscles of the forearm.

\section{CONCLUSIONS}

Palsy of the anterior interosseous nerve is usually characterized by isolated weakness of the flexor pollicis longus, flexor digitorum profundus to the index and middle fingers, and pronator quadratus muscles without sensory loss. The palsy results either from a penetrating injury or from compression by some anomalous anatomical struc- ture. It may also result from external pressure and is then likely to resolve spontaneously within a period of 19 months. Hence, surgical exploration is not always required. Clinical neurophysiological investigation is indicated to confirm the diagnosis. It may reveal subclinical abnormalities in muscles which are supplied by the anterior interosseous nerve.

Dr R. G. Paley kindly gave permission for details of case 1 and Mr R. P. Sengupta and Mr L. P. Lassman permission for details of case 2 to be reported. Dr D. C. Thursh performed the clinical neurophysiological investigations in case 2. Professor J. N. Walton and Dr D. D. Barwick read the manuscript and made many helpful suggestions.

\section{REFERENCES}

Davies, D. V., and Coupland, R. E. (eds) (1967). Gray's Anatomy, Descriptive and Applied, p. 1203. 34th edn. Longmans: London.

Earl, C. J., Fullerton, P. M., Wakefield, G. S., and Schutta, H. S. (1964). Hereditary neuropathy, with liability to pressure palsies. A clinical and electrophysiological study of four families. Quarterly Journal of Medicine, 33, 481-498.

Farber, J. S., and Bryan, R. S. (1968). The anterior interosseous nerve syndrome. Journal of Bone and Joint Surgery 50A, 521-523.

Fearn, C. B. d'A., and Goodfellow, J. W. (1965). Anterior interosseous nerve palsy. Journal of Bone and Joint Surgery, 47B, 91-93.

Gantzer, C. F. L. (1813). Dissertatio anatomica musculorum varietates sistens. Thesis. J. F. Starckii: Berolini.

Gruber, W. (1870). Über die Verbindung des Nervus medianus mit dem Nervus ulnaris am Unterarme des Menschen und der Säugethiere. Archiv für Anatomie, Physiologie und Wissenschaftliche Medicin, 37, 501-522.

James, J. I. P. (1949). A case of rupture of flexor tendons secondary to Kienböck's disease. Journal of Bone and Joint Surgery, 31B, 521-523.

Kiloh, L. G., and Nevin, S. (1952). Isolated neuritis of the anterior interosseous nerve. British Medical Journal, 1, 850-851.

Lipscomb, P. R., and Burleson, R. J. (1955). Vascular and neural complications in supracondylar fractures of the humerus in children. Journal of Bone and Joint Surgery, 37A, 487-492.

Mannerfelt, L. (1966). Studies on the hand in ulnar nerve paralysis. A clinical-experimental investigation in normal and anomalous innervation. Acta Orthopaedica Scandinavica, Suppl. 87, 23-25 and 130-142.

Martin, R. (1763). Tal, om nervers allmänna Egenskaper $i$ Människans kropp. Salvius: Stockholm.

Mills, R. H. B., Mukherjee, K., and Bassett, I. B. (1969). Anterior interosseous nerve palsy. British Medical Journal, 2, 555.

O'Brien, M. D., and Upton, A. R. M. (1972). Anterior interosseous nerve syndrome. Journal of Neurology, Neurosurgery, and Psychiatry, 35, 531-536.

Page, C. M. (1923). An operation for the relief of flexion- 
contracture in the forearm. Journal of Bone and Joint Surgery, 5, 233-234.

Parsonage, M. J., and Turner, J. W. A. (1948). Neuralgic amyotrophy. The shoulder-girdle syndrome. Lancet, 1 , 973-978.

Schmidt, H., and Eiken, O. (1971). The anterior interosseous nerve syndrome. Case reports. Scandinavian Journal of Plastic and Reconstructive Surgery, 5, 53-56.

Seyffarth, H. (1951). Primary myoses in the M. pronator teres as cause of lesion of the $\mathrm{N}$. medianus (the pronator syndrome). Acta Psychiatrica et Neurologica Scandinavica, Suppl. 74, 251-254.

Sharrard, W. J. W. (1968). Anterior interosseous neuritis. Report of a case. Journal of Bone and Joint Surgery, 50B, 804-805.

Spinner, M. (1970). The anterior interosseous-nerve syndrome. With special attention to its variations. Journal of Bone and Joint Surgery, 52A, 84-94.

Spinner, M. (1972). Injuries to the Major Branches of Peripheral Nerves of the Forearm, pp. 77-97. Saunders: Philadelphia.

Spinner, M., and Schreiber, S. N. (1969). Anterior interosseous-nerve paralysis as a complication of supra- condylar fractures of the humerus in children. Journal of Bone and Joint Surgery, 51A, 1584-1590.

Stern, M. B., Rosner, L. J., and Blinderman, E. E. (1967) Kiloh-Nevin syndrome. Report of a case and review of the literature. Clinical Orthopaedics, 53, 95-98.

Sunderland, S. (1945). The innervation of the flexor digitorum profundus and lumbrical muscles. Anatomical Record, 93, 317-321.

Sunderland, S. (1968). Nerves and Nerve Injuries, pp. 742-743 and 748-749. Livingstone: Edinburgh.

Thomas, D. F. (1962). Kiloh-Nevin syndrome. (Abstract.) Journal of Bone and Joint Surgery, 44B, 962.

Thompson, A. (1893). Third annual report of the Committee of Collective Investigation of the Anatomical Society of Great Britain and Ireland for the year 1891-92. Journal of Anatomy and Physiology, 27, 183-194.

Warren, J. D. (1963). Anterior interosseous nerve palsy as a complication of forearm fractures. Journal of Bone and Joint Surgery, 45B, 511-512.

Wilson, S. A. K. (1954). Neuritis. In Neurology, vol. 1, pp. 354-359. 2nd edn. Edited by A. N. Bruce. Butterworth: London. 